\title{
The WAIS Assistant: A Windows Program to Aid in Writing WAIS-III Reports
}

\author{
Barry A. Tanner* \\ Life Stress Center, Detroit Receiving Hospital, USA
}

\begin{abstract}
The WAIS Assistant is intended to facilitate reporting the results of testing with the Wechsler Adult Intelligence Scale-Third Edition. The Assistant does not send output directly to a printer, but rather writes output to a file, in order to encourage editing and inclusion of additional information. The program is available only upon certification that the requestor meets the author's rules for its use, including professional status and appropriate training. Finally, research is encouraged by making the program available to qualified psychologists at no charge.
\end{abstract}

\section{INTRODUCTION}

The Wechsler scales have been the cognitive tests most frequently used by psychologists for at least the last 35 years (Butler PPRP 1991) [1]; (Camara PPRP 2000) [2]; (Daniel AP 1997) [3]; (Kaufman E 2001) [4]; (Rabin ACN 2005) [5]; (Sullivan JCP 1997) [6]. Administering tests takes the largest portion of psychologists' assessment time, with interpretation and report writing close behind and requiring more time than scoring tests and interviewing patients (Sweet CN 2002) [7]. Therefore, the use of PCs to assist in interpreting tests and writing reports offers the potential for saving time second only to computer assisted testing.

Indeed, the publisher of the Wechsler Adult Intelligence Scale - Third Edition or WAIS-III (Wechsler PC 1997) [8] sells a computer program to assist with interpretation and report writing for that test and two related adult scales (WAIS-III-WMS-III-WIAT-II writer, 2002) [9]. In contrast, the WAIS Assistant described in the remainder of this paper aids in the interpretation of only the WAIS-III and preparation of a report based on it, but is available at no cost.

\section{TARGET AUDIENCE}

Matarazzo (Matarazzo CHB 1985) [10], (Matarazzo AP 1986) [11] has expressed concern that scoring services and PC programs may be used by professionals with insufficient training in testing to appreciate the limitations of computer generated interpretations. Similarly, Fowler (Fowler JCCP 1985) [12] pointed out that we lack clear standards regarding who is qualified to use psychological tests, although the American Psychological Association (APA Guidelines 1986) [13] has published guidelines for computer-based test interpretations.

In light of this, the Assistant is available only to psychologists licensed at the independent practice level, who report training in and competence with the WAIS-III. They

*Address correspondence to this author at the Detroit Receiving Hospital, USA; Tel 313-745-4811; Fax 313-966-7196; E-mail : btanner@dmc.org may then use the Assistant personally or supervise its use by unlicensed persons. The expectation is that professional psychologists and psychologists in training will be aware of the limitations of computer generated test interpretation, thereby reducing the likelihood of uncritical acceptance of such interpretation (Honaker CHB 1986) [14]; (Prince JP 1990) [15]. This is consistent with the conclusions of a survey of current assessment practices (McMinn A 1999) [16], as well as with a review of the validity of computer-generated psychological reports (Butcher PA 2000) [17], i.e., that such reports should supplement rather than replace clinical judgment. In keeping with this, the Assistant does not output directly to a printer, but rather to a rich text format (rtf) file to facilitate editing the results and merging them with other test and interview data.

To further encourage good practice, the Assistant is to be used only when testing with the complete WAIS-III. The Assistant is not to be used with abbreviated forms of the WAIS, because the decreased reliability of short forms as well as questions regarding the application of norms to them limits their use to little more than estimates of global IQ (Lezak NA 1995) [18]. Furthermore, the Assistant produces statements based upon the statistical significance of differences between subtests which will not be accurate for versions which eliminate items. However, such restrictions may be insufficient, as psychologists are almost evenly divided on the ethics of using text generated by computers in reports written by psychologists [16].

\section{USE OF THE PROGRAM}

The user enters identifying data regarding the patient along with scaled scores, IQs, indexes and confidence intervals for the IQs and indexes. The user must obtain these standardized scores from the WAIS-III manual (Wechsler WAIS 1997) [8] because they are based upon copyrighted normative data. The psychologist also selects the .01 or .05 level of significance to use when examining differences between scores, and the $90 \%$ or $95 \%$ confidence level to be used when determining the interval likely to contain the examinee's true as opposed to obtained score. 
Fig. (1) shows the information entered for a hypothetical 37 -year-old man, with a $5 \%$ significance level and a $90 \%$ confidence interval selected. The Assistant sets a more stringent default value $(5 \%)$ for the significance of the difference between IQs or Indexes than for confidence intervals surrounding individual IQs or Indexes (90\%), given that difference scores are less reliable than individual scores (Magnusson TT 1967) [18]. Users may set more restrictive levels of $1 \%$ and $95 \%$ if they wish. The hypothetical subject obtained verbal scaled scores ranging from 5 to 15 and performance scaled scores ranging from 6 to 14 . He obtained a Verbal IQ of 108 , with a $90 \%$ confidence interval of 104 to 112 . The psychologist has not entered the raw number of digits recalled nor the percentile scores for three optional measures.

When the psychologist clicks on the report menu a standard Windows file save dialog appears. The program saves the output to a file under a name indicated by the psychologist. That file may then be read and edited with most word processors.

Fig. (2) shows the original report opened in Microsoft Word XP for this sample patient. The scores are organized in a traditional manner, with parenthetical letters identifying scores that represent a relative strength (S) or weakness (W) for the patient based upon the $5 \%$ significance level shown as selected in Fig. (1). For example, Mr. Smith's scaled score of 9 on Arithmetic is significantly weaker than the mean of his verbal scores, while his scaled score of 13 on Picture Arrangement is significantly stronger than the mean of his non-verbal or performance scores.

Following the scores, the report provides a brief introduction to the WAIS-III, followed by a description of the subject's performance on the test. After that description, the report generally follows the interpretive steps described by Kaufman \& Lichtenberger (Kaufman EWA 1999) [20]. It begins with the Full Scale IQ and whether or not that single measure can be considered representative of this subject's cognitive abilities. If the Verbal and Performance IQs or the Verbal Comprehension and Perceptual Organization Indexes differ significantly, the report indicates that the Full Scale IQ should not be considered representative of the subject's intellectual functioning and that one should look at the verbal and non-verbal skills separately. The Assistant compares the subject's scores with those for the average of the total standardization sample at the chosen significance level (.10 or .05) rather than the .15 level listed in Wechsler (1997), because the .15 level contains excessive error [20].

Assuming that the verbal-nonverbal difference is statistically significant, the Assistant then determines if it is abnor-

G. WAIS Assistant

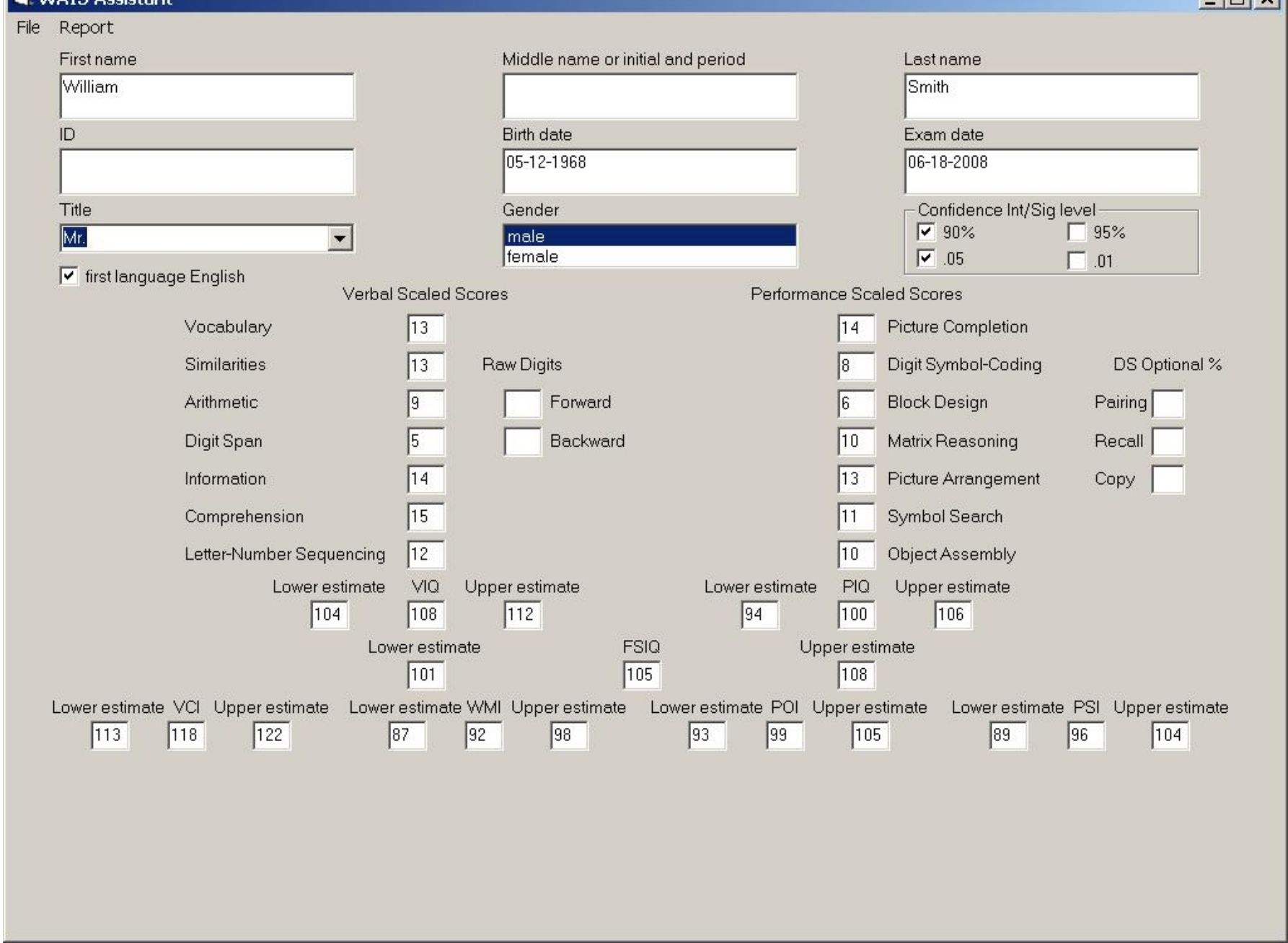

Fig. (1). Screen with data. 


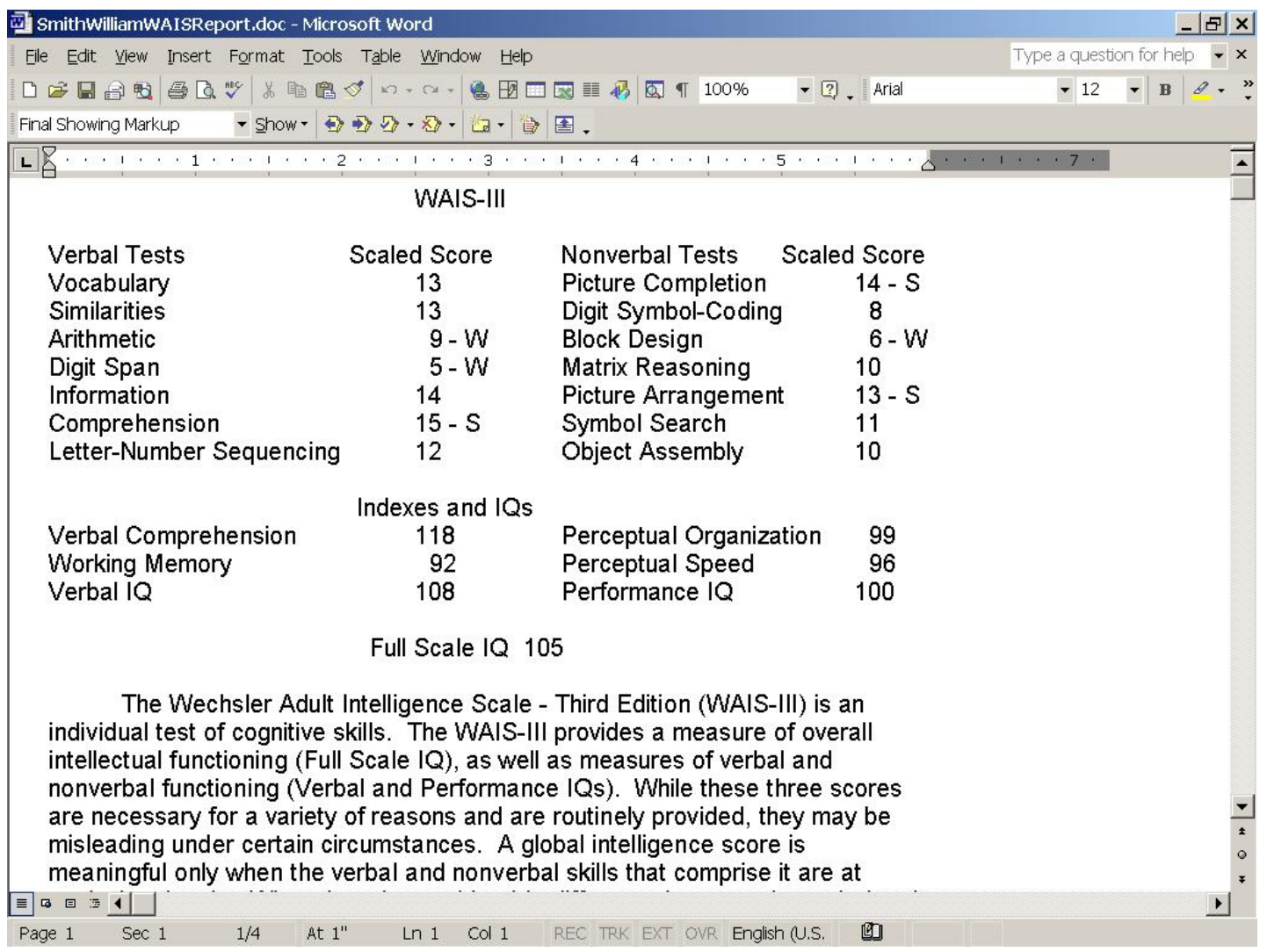

Fig. (2). Sample output.

mally large, since more than $25 \%$ of normal adults have a Verbal versus Performance IQ discrepancy that is significant at the .01 level or beyond [20]. That is, a given difference may be statistically significant while not unusual or infrequent in comparison to the WAIS-III standardization sample. The report labels a VIQ-PIQ difference of at least 17 points and a VCI-POI difference of at least 19 points as abnormal, since these differences correspond to approximately one standard deviation above the mean of the standardization sample [20].

The Assistant then determines if the subject's verbal and nonverbal skills can each be represented by a single score. If the factors making up either the VIQ or the PIQ differ significantly, or if the range of the scaled scores within either of the IQs is 8 or greater (approximately one standard deviation above the mean for the standardization sample per Wechsler [8]), the report states that the IQ represents diverse abilities that cannot be represented by a single score [20].

Next, the report describes the subject's individual scores, commenting on relative strengths and weaknesses compared to the individual's average performance. That is, a given score may be average or better compared to the standardization sample, but a relative weakness for the individual whose mean is high (WAIS 2002) [21]. These comments include descriptions of the tasks involved in the subtests and of the skills believed to be involved in these tasks. The report may also offer possible explanations for the subject's performance on the WAIS and then briefly summarizes the material previously presented.

Fig. (3) shows page 2 of the sample report in Word. The first paragraph discusses the factors comprising his VIQ and points out that these two Indexes or factors are not equivalent and therefore do not represent evenly developed skills. The next paragraph deals with the two factors making up the PIQ, concluding that the Perceptual Organization Index and Processing Speed Index are equivalent.

\section{REQUIREMENTS}

The Assistant is written in Microsoft Visual Basic 6 and requires about a $\mathrm{MB}$ of drive space. The program has been tested with Windows 2000 and XP, but not with other versions of Windows.

The program is available at no charge to qualified psychologists who agree to abide by the author's conditions for its use. Potential users should send the author a written request for a copy of the WAIS Assistant in which they state that they hold an earned degree in psychology and that they are licensed at the independent practice level in the location where they will use the program. They must also state that they have been trained in the administration and interpretation of the WAIS-III and are competent in the use of the test. In addition, they must also agree that the Assistant will be used only for patients who have been administered the standard WAIS-III and that all output from the program will be rewritten under their supervision to include additional information about the patients. They must agree not to use the Assistant for "blind" interpretation of data from other healthcare providers' patients. Deviations from this may be allowed only for research projects approved by the requestor's Human Investigation Committee. Although they may copy the program for allowed use under their personal supervision, they may not distribute it to other persons, may not 


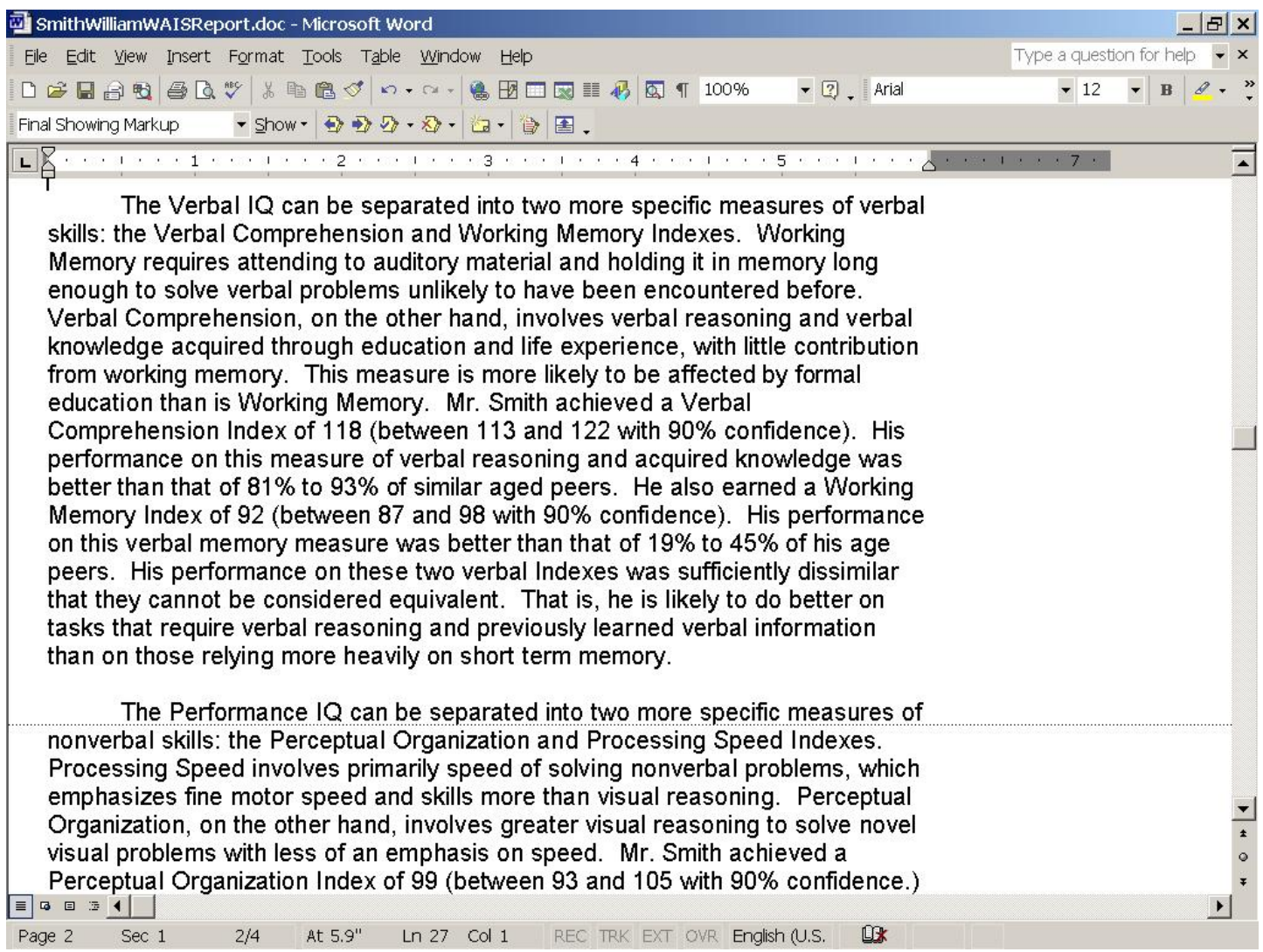

Fig. (3). Additional sample output.

modify the program and may not include any or all of it in other programs. Finally, requests should be made by e-mail.

\section{REFERENCES}

[1] Butler M, Retzlaff P, Vanderploeg R. Neuropsychological test usage. Prof Psychol Res Prac 1991; 22: 510-12.

[2] Camara WJ, Nathan JS, Puente AE. Psychological test usage: Implications in professional psychology. Prof Psychol Res Prac 2000; 31: 141-54.

[3] Daniel MH. Intelligence testing: Status and trends. Am Psychol 1997; 52: 1038-45.

[4] Kaufman AS, Kaufman JC. Emotional intelligence as an aspect of general intelligence: What would David Wechsler say? Emotion 2001; 1: 258-64.

[5] Rabin LA, Barr WB, Burton LA. Assessment practices of clinical neuropsychologists in the United States and Canada: a survey of INS, NAN, and APA Division 40 members. Arch Clin Neuropsychol 2005; 20: 33-65.

[6] Sullivan K, Bowden SC. Which tests do neuropsychologists use? J Clin Psychol 1997, 53: 657-61.

[7] Sweet JJ, Peck EA, Abramowitz C, Etzweiler S. National Academy of Neuropsychology/Division 40 of the American Psychological Association practice survey of clinical neuropsychologists in the United States, Part I: Practitioner and practice characteristics, professional activities and time requirements. Clin Neuropyschol 2002; 16: 109-27.

[8] Wechsler D. WAIS-III: Wechsler Adult Intelligence Scale - Third Edition. 1997; San Antonio TX: Psychological Corporation..
[9] WAIS-III-WMS-III-WIAT-II writer 2002; San Antonio TX: Psychological Corporation.

[10] Matarazzo JD. Clinical psychological test interpretations by computer. Hardware outpaces software. Comput Human Beh 1985; 1: 235-53.

[11] Matarazzo JD. Computerized clinical psychological test interpretations. Am Psychol 1986; 41: 14-24.

[12] Fowler RD. Landmarks in computer-assisted psychological assessment. J Consult Clin Psychol 1985; 53: 748-59.

[13] Guidelines for computer-based tests and interpretations. 1986; Washington DC: American Psychological Association.

[14] Honaker LM, Hector VS, Harrell TH. Perceived validity of computer-versus clinician-generated MMPI reports. Comp Hum Beh 1986; 2: 77-83.

[15] Prince RJ, Guastello SJ. The Barnum effect in a computerized Rorschach interpretation system. J Psychol 1990; 124: 217-22.

[16] McMinn MR, Ellens BM, Soref E. Ethical perspectives and practice behaviors involving computer-based test interpretation. Assess 1999; 6: 71-7.

[17] Butcher JN, Perry JN, Atlis MM. Validity and utility of computerbased test interpretation. Psychol Assess 2000; 12: 6-18.

[18] Lezak MR. Neuropsychological assessment (Third Edition). 1995; New York: Oxford U Press.

[19] Magnusson D. Test theory. 1967; Reading MA: Addison-Wesley.

[20] Kaufman AS, Lichtenberger EO. Essentials of WAIS-III assessment. 1999; New York: Wiley.

[21] WAIS-III WMS-III technical manual 2002; San Antonio TX: Psychological Corporation.

(C) Barry A. Tanner; Licensee Bentham Open.

This is an open access article distributed under the terms of the Creative Commons Attribution License (http://creativecommons.org/licenses/by/2.5/), which permits unrestrictive use, distribution, and reproduction in any medium, provided the original work is properly cited. 